\title{
Seção geológica Manaus - Presidente Figueiredo (AM), borda norte da Bacia do Amazonas: um guia para excursão de campo
}

\author{
Valmir da Silva Souza ${ }^{1}$ \& Afonso César Rodrigues Nogueira ${ }^{2}$
}

\begin{abstract}
Resumo A rodovia BR-174 entre os municípios de Manaus e Presidente Figueiredo, Estado do Amazonas, é uma das rotas mais didáticas para a observação da geologia da Amazônia Ocidental. Esta rodovia é uma "janela" que corta a densa floresta amazônica expondo rochas que abrangem idades desde o Proterozóico ao Cenozóico, possibilitando compreender a história geológica da borda norte da Bacia do Amazonas e sua relação com o embasamento cristalino do sul do Escudo das Guianas. Foram reconhecidos dois sucessivos eventos magmáticos ocorridos entre 1,90 e 1,81 Ga: a) suíte cálcio-alcalina Água Branca, do tipo I e sin-colisional (1.90-1.89 $\mathrm{Ga}$ ); e b) magmatismo do tipo A, pós-colisional a anorogênico, representado pelo vulcano-plutonismo alcalino Iricomé-Mapuera (1.88-1.87 Ga) e granitos Moderna-Madeira (1.82-1.81 Ga). O final do Proterozóico foi marcado por tectônica distensiva com a formação da bacia Prosperança preenchida por depósitos flúvio-costeiros. No EoPaleozóico, eventos transtensivos geraram as fases rifte/sinéclise da bacia intracratônia do Amazonas, permitindo uma espessa sedimentação costeira a marinha parcialmente influenciada por glaciações. No final do Mesozóico um sistema fluvial-lacustre foi instalado na região e durante o Cenozóico a região foi afetada pelos ciclos de lateritização/bauxitização. Posteriormente, a tectônica transtensiva quaternária gerou soerguimento e abatimento de blocos estruturais na região com a formação de depósitos colúvio-aluvionares.
\end{abstract}

Palavras-chave: Seção geológica; Manaus; Presidente Figueiredo; Bacia do Amazonas; sul do Escudo das Guianas; estado do Amazonas.

\begin{abstract}
Geologic section between Manaus and Presidente Figueiredo districts, State of Amazonas, Brazil, northern border of the Amazonas basin: a field trip guide. The BR-174 highway between Manaus and the town of Presidente Figueiredo, State of Amazonas, is one of the best places to study the geology of Western Amazonia. This highway is a "window" in the dense rainforest that gives insight along roadcuts into Proterozoic to Cenozoic rocks, which allow to comprehend the geologic history of the northern border of the Amazon basin and its relation with the crystalline basement of southern Guyanas shield. Two successive magmatic events were recognized and dated between 1,90 and 1,81 Ga: a) the syn-collisional Água Branca calco-alkaline suite of I-type (1,90-1,89 Ga); and b) the post-collisional to anorogenic magmatism of A-type, represented by Iricoumé-Mapuera alkaline volcanic-plutonism (1,88-1,87 Ga) and Moderna-Madeira granites $(1,82-1,81 \mathrm{Ga})$. The final stage of the Proterozoic eon was marked by distensional tectonics and development of The Prosperança basin, filled with fluvial and coastal deposits. During the Early Paleozoic, a rift-syneclise phase generated the intracratonic Amazon basin filled with thick coastal to marine deposits which were influenced by glacial events. The end of The Mesozoic era was marked by the implantation of a fluvial-lacustrine depositional system, while in the Cenozoic era, the region was affected by intense lateritization/bauxitization events. Subsequently, transtensive Quaternary tectonics promoted a relief reconfiguration with the deposition of colluvial-alluvial deposits.
\end{abstract}

Keywords: Geological section; Manaus; Presidente Figueiredo; Amazonas basin; southern Guyana Shield; State of Amazonas.

INTRODUÇÃO Na Amazônia ocidental brasileira, devido às dificuldades de acesso, desenvolvimento de solos espessos e densa cobertura de floresta, somente em algumas áreas é possível observar as relações litoestratigráficas e estruturais entre diferentes tipos de rochas. Uma dessas áreas envolve parte dos municípios de Manaus e Presidente Figueiredo, região nordeste do Estado do Amazonas, na qual está exposto um empi- lhamento estratigráfico que abrange rochas do Paleoproterozóico ao Fanerozóico (Fig. 1). Entretanto, tal exposição só foi possível devido à abertura da rodovia federal BR-174, entre as décadas de 1970 e 1980, ligando as capitais Manaus (AM) - Boa Vista (RR). Neste período surgem também os primeiros trabalhos de integração das informações geológicas na região (Araújo et al. 1976, Santos et al. 1974, Araújo Neto \& Moreira

1 - Universidade de Brasília, Instituto de Geociências, Brasília (DF) / Programa de Pós-Graduação em Geociências da Universidade Federal do Amazonas, Manaus (AM), Brasil. E-mail: e-mail: vsouza@unb.br

2 - Universidade Federal do Pará, Instituto de Geociências, Faculdade de Geologia, Belém (PA), Brasil. E-mail: anogueira@ufpa.br 
1976, Veiga Jr. et al. 1979, Costi et al. 1984, Caputo et al. 1972, Caputo \& Sad inédito, Souza 1974 e Caputo 1984). A partir da década de 1990 , com a pavimentação da rodovia BR-174, novas vicinais foram abertas e expuseram melhor as relações litoestratigráficas e estruturais entre os diferentes tipos rochosos, favorecendo o aprofundamento nas investigações geológicas na região (Nogueira et al. 1997a e 1997b, Monteiro et al. 1998, Soares 1998, Horbe et al. 2001, CPRM 2002, Valério 2006, Peixoto 2006, Almeida 2006, Reis et al. 2006).

Este trabalho apresenta um roteiro-guia para excursões geológicas de campo, auxiliando no entendimento das relações litoestratigráficas e estruturais desde as rochas sedimentares fanerozóicas da borda norte da Bacia do Amazonas até as rochas paleoproterozóicas do embasamento cristalino do sul do Escudo das Guianas. A base de dados deste trabalho é formada por um conjunto de seções geológicas elaboradas ao longo de diferentes trechos da rodovia BR-174, utilizando principalmente exposições em cortes de estrada e frentes de lavra de pedreiras. Este trabalho apresenta também algumas considerações a respeito de problemas geológicos ainda pouco investigados na região, envolvendo principalmente a natureza dos eventos magmáticos e deformacionais paleoproterozóicos, bem como a respeito da idade de alguns depósitos sedimentares.

CONTEXTO GEOLÓGICO REGIONAL A carência de informações geológicas em várias áreas da região Amazônica tem conduzido às freqüentes atualizações e revisões das propostas de subdivisão geológica do Cráton Amazônico, principalmente em face aos novos dados de mapeamento geológico, levantamentos aerogeofísicos e informações geocronológicas (Sm$\mathrm{Nd}, \mathrm{Pb}-\mathrm{Pb}, \mathrm{U}-\mathrm{Pb}$ ). Atualmente as duas propostas mais aceitas subdividem o Cráton Amazônico em províncias geocronológicas, cuja evolução envolveu ciclos orogenéticos com retrabalhamento de crosta continental e adição de material juvenil, conduzidos por mecanismos da moderna tectônica de placas (Tassinari \& Macambira 1999 e 2004, Tassinari et al. 2000, Santos et al. 2000 e 2001a, Santos 2003).

A região nordeste do Estado do Amazonas abrange o contexto geológico limítrofe entre o embasamento cristalino paleoproterozóico e a pilha de rochas sedimentares fanerozóicas que constituem a parte norte da Bacia do Amazonas (Fig. 1). As rochas do embasamento paleoproterozóico estão inseridas no contexto da província Tapajós-Parina (Fig. 1), com base na proposta de Santos et al. (2000 e 2001a) e Santos (2003), cuja evolução envolveu a agregação de sucessivos arcos magmáticos durante 2.10 a $1.87 \mathrm{Ga}$ e que foram aglutinados ao núcleo do cráton formado pela província Amazônia Central. Com base em similaridades petrológicas, geocronológicas e metalogenéticas, Santos et al. (2001a) e Santos (2003) propuseram a subdivisão da província Tapajós-Parina nos domínios Alta Floresta, Tapajós, Uaimiri e Parima. A região nordeste do Estado do Amazonas está inserida no domínio Uaimiri, cujas rochas estão, em grande parte, encobertas pela espes- sa sedimentação siliciclástica marinha a fluvial ocorrida durante a evolução da Bacia do Amazonas (Fig. 1). As rochas do domínio Uaimiri exibem marcantes correlações genéticas e geocronológicas com as rochas do domínio Tapajós, porém em relação às rochas dos domínios Alta Floresta e Parima tais correlações são apenas parciais.

Santos et al. (2006), em uma revisão simplificada da compartimentação geocronológica e geotectônica do Cráton Amazônico, propõem a expansão dos limites geográficos da província Tapajós-Parina para leste a para norte, subdividida nos domínios Matupá (em substituição ao termo Alta Floresta), Tapajós, Uaimiri e Parima.

LITOESTRATIGRAFIA DA ÁREA O quadro litoestratigráfico no trecho Manaus-Presidente Figueiredo abrange unidades paleoproterozóicas constituídas por rochas gnáissicas, graníticas e vulcânicas (Complexo Jauaperi, Suíte Intrusiva Água Branca, Grupo Iricoumé, Suíte Intrusiva Mapuera e Suíte Intrusiva Madeira), sobrepostas por rochas sedimentares neoproterozóicas (Formação Prosperança) e fanerozóicas (grupos Trombetas e Javari). Completam esse quadro, intrusões básicas de idades ainda incertas, coberturas lateríticas e depósitos colúvio-aluvionares do Cenozóico.

As unidades paleoproterozócas estão distribuídas desde o sul-sudeste de Roraima até noroeste do Pará, formando, em geral, um relevo dissecado com colinas de altitude entre 70 e $120 \mathrm{~m}$. O Complexo Jauaperi reúne ortognaisses, migmatitos, metagranitos, anfibolitos e charnoquitos, cujos estudos geocronológicos $\mathrm{U}-\mathrm{Pb}$ revelam idades entre 1.86 e $1.88 \mathrm{Ga}$, valores estes muito próximos aos obtidos para os eventos magmáticos Água Branca, Iricoumé e Mapuera (Santos et al. 1974, Faria \& Luzardo 2000, Santos et al. 2001b, Valério 2006, Almeida 2006, Reis et al. 2006). A Suíte Intrusiva Água Branca reúne granitos a granodioritos cinza claros, equigranulares a porfiríticos médios a grossos, portadores de hornblenda e/ou biotita, além de dioritos a quartzo-dioritos, apresentando composições meta a peraluminosa e idade de $1.89 \mathrm{Ga}$ (Oliveira et al. 1996, Faria et al. 2000, Almeida \& Macambira 2003, Valério 2006, Almeida 2006). O Grupo Iricoumé é constituído por depósitos de fluxos piroclásticos intercalados com derrames vulcânicos ácidos a intermediários de natureza subalcalina e idade entre 1.89 e 1.88 Ga (Araújo Neto \& Moreira 1976, Veiga Jr. et al. 1979, Costi et al. 2000, Santos et al. 2002, Valério 2006, Ferron 2006). Já a Suíte Intrusiva Mapuera reúne batólitos e stocks de composição monzo a sienogranitos, quartzo sienitos, monzonitos e granófiros de cor rósea a acinzentada, com textura equigranular a porfirítica média a grossa, assinatura geoquímica meta a peraluminosa e idade entre 1.88 e $1.86 \mathrm{Ga}$ (Geomineração inédito, Araújo Neto \& Moreira 1976, Veiga Jr. 1979, Costi et al. 1984, João et al. 1984, Valério 2006). Outro importante episódio magmático reúne os stocks graníticos da suíte Madeira, encontrados no distrito minerador do Pitinga, os quais exibem composição alcalina, natureza anorogênica intra-placa, ida- 


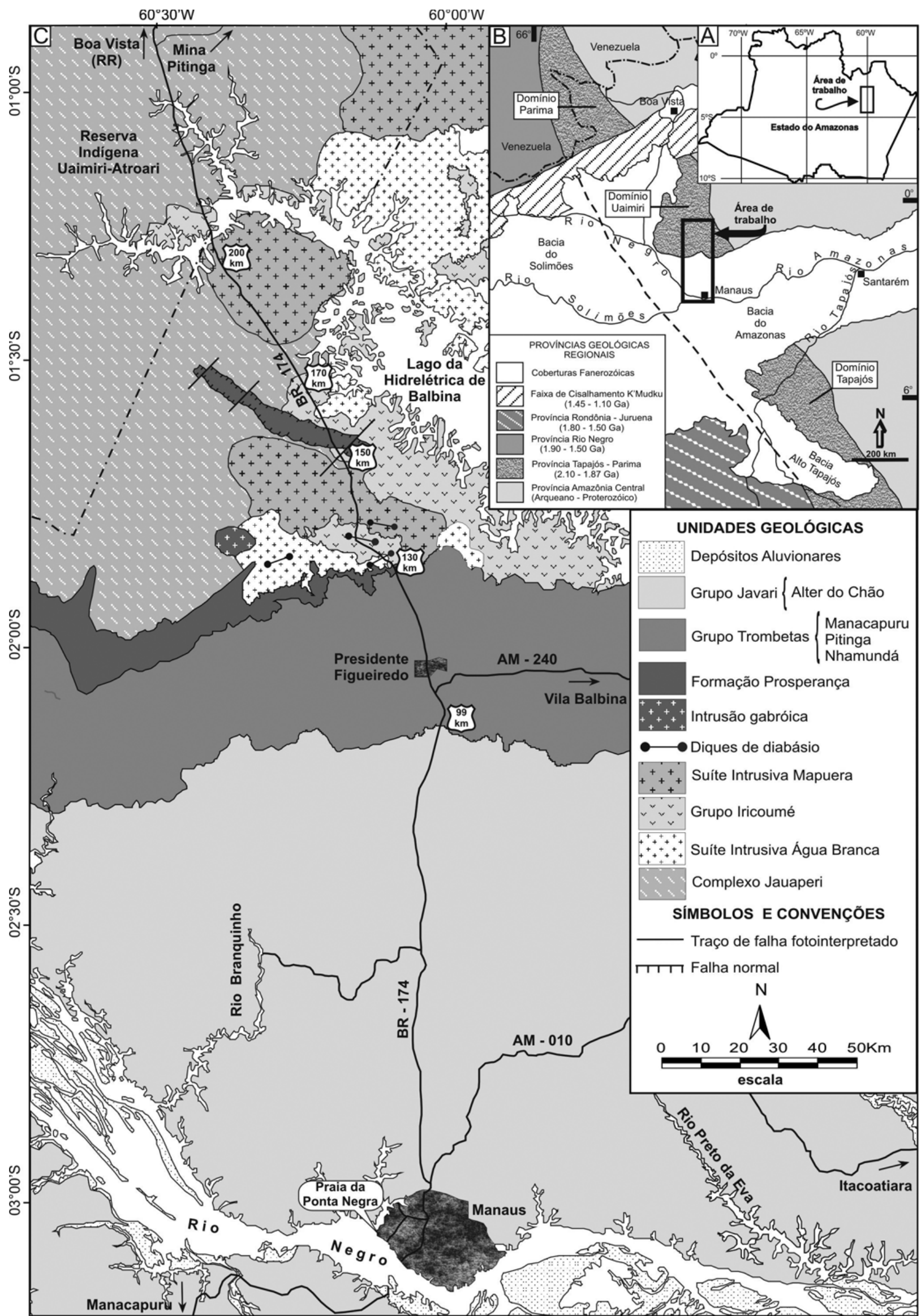

Figura 1 - A) localização geográfica da área de trabalho; $B$ ) de contexto geológico regional (modificado de Santos 2003); C) mapa geológico da área de trabalho, ressaltando o trajeto ao longo da BR-174 onde foram elaboradas as seções geológicas (modificado de CPRM 2002). 
des entre 1.83 e $1.80 \mathrm{Ga}$ e hospedam mineralizações polimetálicas de Sn, Zr, Nb-Ta, ETR, Y e F (Fuck et al. 1993, Macambira et al. 1987, Lenharo 1998, Costi et al. 2000, Ferron 2006).

As unidades sedimentares, por sua vez, formam um relevo residual entalhado pela drenagem, apresentando vales amplos e interflúvios tabulares, com locais feições pseudocársticas e com altitudes entre 60 e 80 $\mathrm{m}$. Essas unidades são testemunhos do evento tectônico distensivo que reativou anisotropias (falhas e fraturas) proterozóicas, gerando fases de rifte/sinéclise que favoreceram a espessa sedimentação da bacia intracratônica do Amazonas (Wanderley Filho 1991, Cunha et al. 1994, Wanderley Filho 1996). A implantação da fase rifte é marcada pela deposição dos sedimentos da Formação Prosperança, a qual representa a primeira sedimentação dos depósitos costeiros-marinhos, enquanto a fase sinéclise é representada pela sedimentação do Grupo Trombetas, o qual foi subdividido, da base para o topo, nas formações Autás-Mirim, Nhamundá, Pitinga e Manacapuru (Caputo 1984, Cunha et al. 1994). Destas unidades sedimentares apenas a Formação AutásMirim não aflora na área objeto deste trabalho.

No intervalo Mesozóico-Cenozóico, são registrados na região magmatismo basáltico a andesítico (Alves et al. 2002) e, principalmente, a sedimentação do Grupo Javari, representado pela Formação Alter do Chão (Eiras et al. 1994), que é a unidade de maior extensão aflorante na Bacia do Amazonas. Durante o Cenozóico, a região foi afetada pelos ciclos de lateritização/bauxitização que produziram espessos latossolos e perfis lateriticos caulínicos e aluminosos sobre as rochas proterozóicas e fanerozóicas (Horbe et al. 1999 e 2001). No final desse período, são também registrados a marcante ação de uma tectônica distensiva e o retrabalhamento de unidades pré-existentes para formar depósitos colúvio-aluvionares arenosos e conglomeráticos encontrados próximos às vertentes de morros e ao longo dos canais das drenagens.

SEÇÕES GEOLÓGICAS O roteiro-guia para excursão de campo aqui apresentado inicia com unidades cenozóicas aflorantes na cidade de Manaus, a partir da praia da Ponta Negra (Fig. 2, seção A), e termina com unidades paleoproterozóicas no quilômetro 200 da rodovia BR-174, próximo à entrada da reserva indígena Uaimiri-Atroari (Fig. 2, seção F). Entretanto, alguns trechos ao longo da rodovia BR-174 foram suprimidos das seções geológicas por apresentarem poucas variações litológicas e estruturais ou carência de exposições de rocha.

Seção Geológica A Esta seção foi elaborada para a zona oeste da cidade de Manaus, bairro da Ponta Negra, contemplando exposições de depósitos aluvionares, além das variações litológicas e os registros da tectônica cenozóica na Formação Alter do Chão (Fig. 2). No período de baixo nível do Rio Negro (meses de setembro a março) são expostas barras arenosas recentes de granulação fina a grossa que formam uma faixa arenosa conhecida como Praia da Ponta Negra (Fig. $3 \mathrm{~A}$ ), as quais encobrem parcialmente afloramentos da Formação Alter do Chão. Os depósitos da Formação Alter do Chão são constituídos por arenitos, argilitos caolinizados e, subordinadamente, conglomerados, contendo, localmente, níveis descontínuos de arenitos silicificados e ferruginosos, com espessura entre 1 e 2 $\mathrm{m}$, denominados informalmente de "Arenito Manaus" (Kistler inédito, Albuquerque 1922). Na Praia da Ponta Negra esses níveis silicificados exibem mosqueamento, desferrificação, bioturbações, gretas de contração e fósseis de madeira que tipificam paleossolos (Vieira 2002, Nogueira et al. 2003). A Formação Alter do Chão é interpretada como produto de um ambiente flúvio-deltaico-lacustre em sistema de rios entrelaçados depositada no Cretáceo Superior (Caputo et al. 1972, Daemon 1975, Travassos \& Barbosa Filho 1990, Cunha et al. 1994 Dino et al. 1999).

No trajeto feito da praia da Ponta Negra em direção ao norte, pela Av. do Futuro, é possível contemplar alguns dos registros da tectônica cenozóica que afetou a região e que tem sido objeto de estudo de vários pesquisadores (Iriondo 1982, Franzinelli \& Piuci 1988, Franzinelli \& Igreja 1990, Fernandes Filho 1996, Costa et al. 1996 e 2001, Silva 2005, entre outros). Nesse trecho, o horizonte de crosta laterítica ferruginosa desenvolvido sobre a Formação Alter do Chão mostrase deslocado por um sistema de falhas normais em arranjo lístrico, gerando estruturas do tipo graben e horst sintéticas e antitéticas, inclusive com rotação de blocos, cujo deslocamento principal está direcionado para SSW (Fig. 3B). Os registros dessa tectônica rúptil estão distribuídos por grande parte da cidade de Manaus e entorno, gerando desníveis topográficos e favorecendo o aparecimento de corredeiras e até cachoeiras em áreas de exposição do "Arenito Manaus", como é o caso da cachoeira Tarumã (Fig. 3C).

$\mathrm{Na}$ rodovia BR-174, saindo da cidade de Manaus em direção a cidade de Presidente Figueiredo, por um trecho de cerca de 85 quilômetros, são encontradas em cortes de estrada e voçorocas, exposições da Formação Alter do Chão lateritizada (Fig. 3D), a qual hospeda depósitos caulim e espodossolos de areias brancas desferrificadas. Segundo Costa \& Moraes (1998), os depósitos de caulim na região ocorrem nos horizontes inferiores dos perfis lateríticos, possuem teores relativamente altos em $\mathrm{SiO}_{2}$ e baixos em $\mathrm{Al}_{2} \mathrm{O}_{3}$, foram desenvolvidos a partir do Paleógeno e apresentam características técnicas para aplicação da indústria de papel. Horbe et al. (2004) consideram que os depósitos de areia branca, amplamente utilizados no setor de construção civil na região, são produtos de podzolização sobre horizontes lateriticos caulinizados, cuja gênese teria ocorrido por volta de 3.000 anos atrás.

Seção Geológica B Esta seção abrange as formações Alter do Chão e Manacapuru, cujas relações de contato estão encobertas por um latossolo creme-amarelado que recobre uma extensa área de platô. Contudo, a partir do quilômetro 96, exposições da Formação Manaca- 

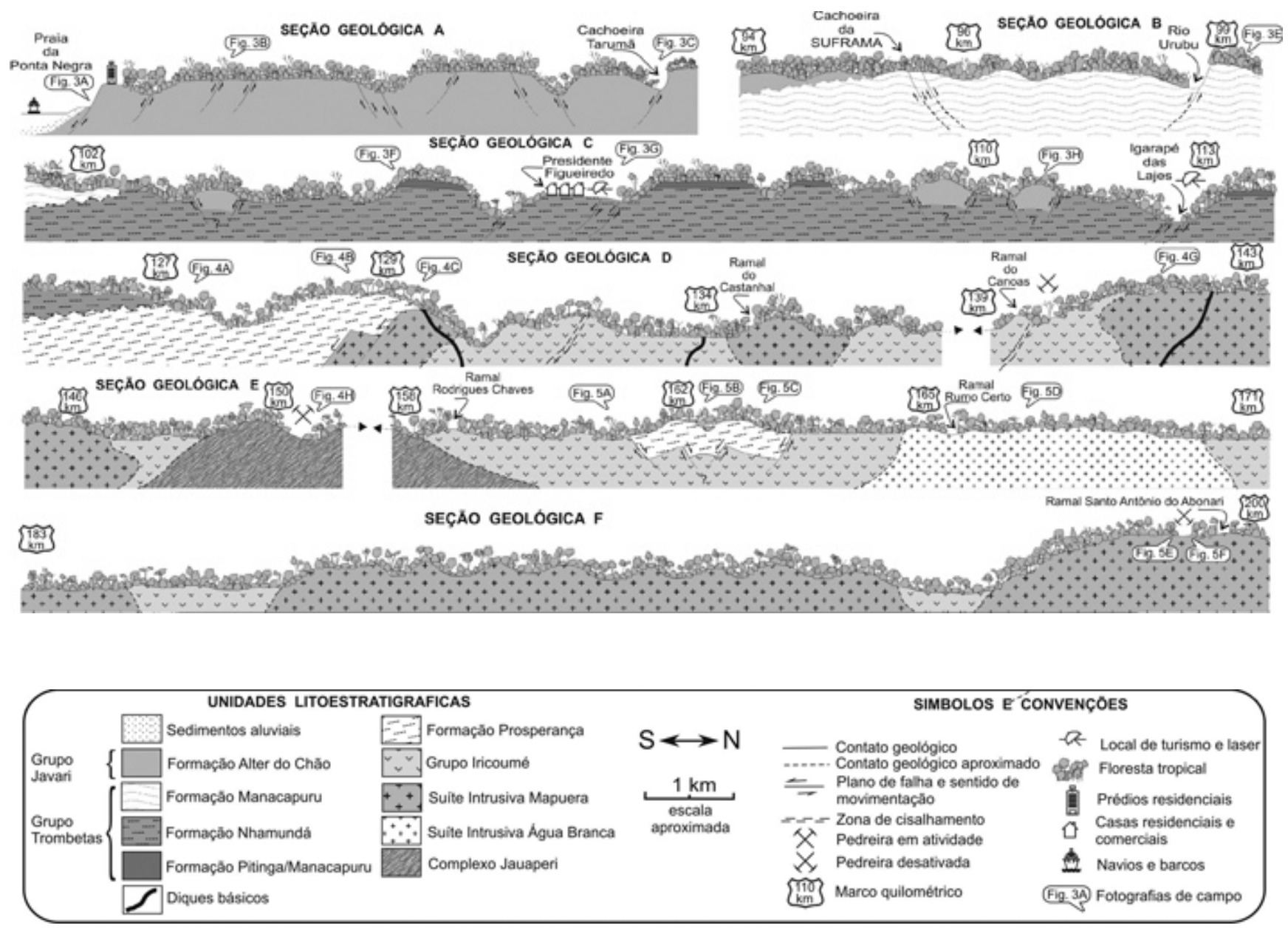

Figura 2 - Seções geológicas elaboradas ao longo de diferentes trechos da rodovia BR-174, partindo da Praia da Ponta Negra (Manaus) até o quilômetro 200 da rodovia BR-174, próximo a entrada da reserva indígena UaimiriAtroari.

puru são encontradas principalmente na cachoeira da SUFRAMA e em corte de estrada da rodovia BR-174, próximo a ponte sobre o Rio Urubu (Fig. 3E). Essa unidade consiste em arenitos finos a médios, folhelhos e siltitos laminados com abundantes icnofósseis, palinomorfos e macrofósseis (principalmente braquiópoda), datados do Devoniano Inferior (Coelho 1984, Soares \& Nogueira 2006, Ramos et al. 2001). A Formação Manacapuru é interpretada como depósito de ambiente litorâneo a marinho nerítico, compondo uma seqüência transgressiva-regressiva de idade siluro-devoniana (Caputo 1984, Cunha et al. 1994).

Seção Geológica C Esta seção esboça as relações de contato entre as unidades paleozóicas do Grupo Trombetas (formações Nhamundá, Pitinga, Manacapuru) e os registros de depósitos cretáceos da Formação Alter do Chão, encaixados em estruturas de abatimento do tipo graben desenvolvidas sobre a Formação Nhamundá (Fig. 2).

O contato entre as formações Manacapuru e Nhamundá é marcado por uma discordância erosiva, o qual está freqüentemente encoberto por espesso latos- solo creme-amarelado. Estudos em palinomorfos provenientes de folhelhos e arenitos expostos nas margens do Rio Urubu, os quais recobrem a Formação Nhamundá, indicam intervalo deposicional do Devoniano inferior, o que permite caracterizar essas rochas como representantes da Formação Manacapuru (Coelho 1984). Entretanto, em outras exposições encontradas na região do Município de Presidente Figueiredo, semelhantes folhelhos e arenitos sobrepostos diretamente sobre a Formação Nhamundá têm sido considerados como pertencentes à Formação Pitinga. Devido a esta incerteza quanto ao posicionamento litoestratigráfico dessas rochas, utilizaremos neste trabalho o termo Formação Pitinga/Manacapuru para caracterizar as outras exposições de folhelhos e arenitos encontradas ao longo da rodovia BR-174.

Próximo à entrada da cidade de Presidente Figueiredo, em corte de estrada do quilômetro 106 da rodovia BR-174, é possível observar o contato erosivo entre as formações Nhamundá e Pitinga/Manacapuru, as quais se mostram lateritizadas (Fig. 3F). Nesse ponto a Formação Nhamundá está representada por diamictitos que exibem estruturas geradas por glaciotectônica, 

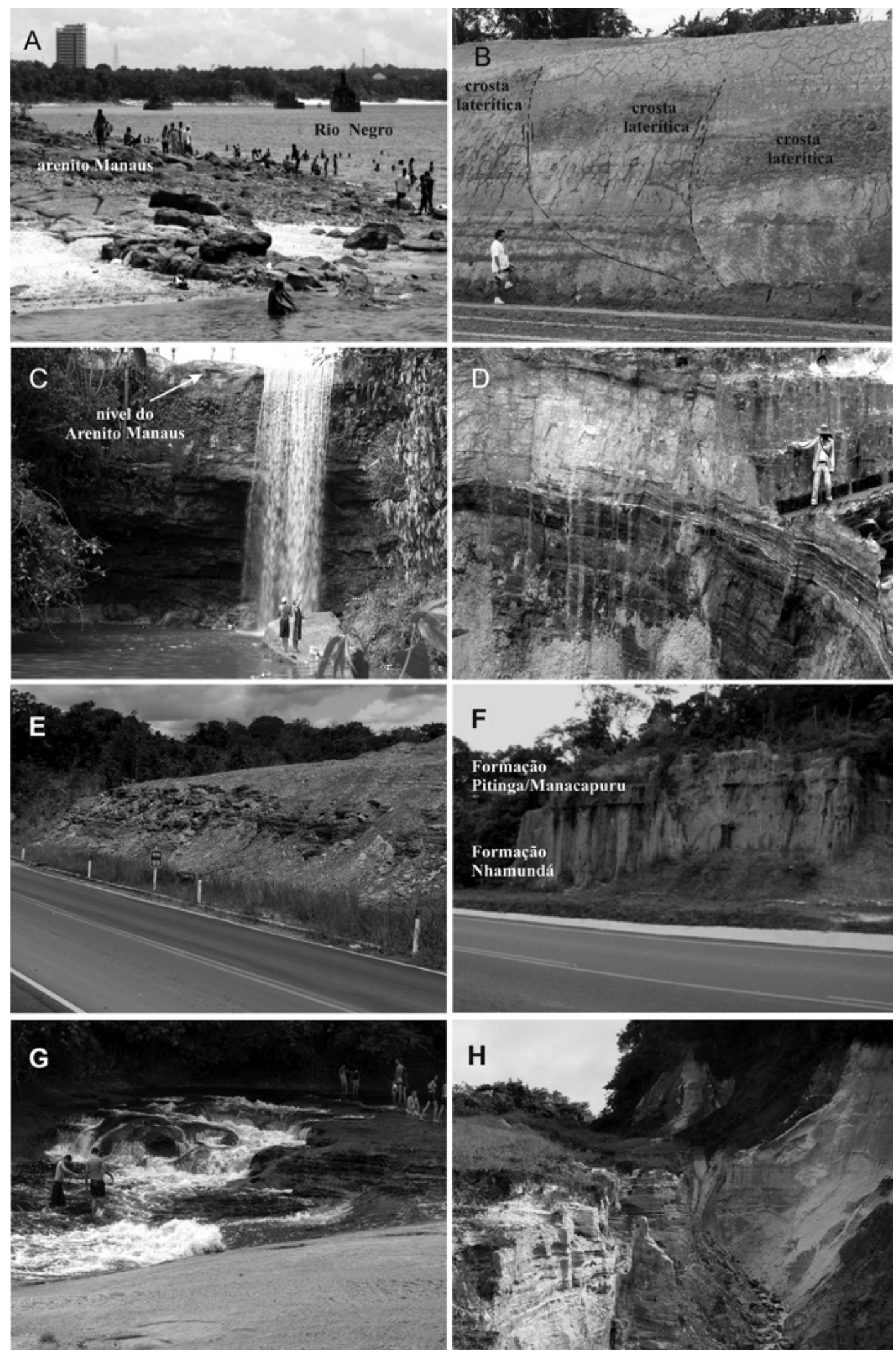

Figura 3 - A) vista da Praia da Ponta Negra exibindo nível do "Arenito Manaus" parcialmente recoberto por sedimentos aluvionares; B) crosta ferruginosa lateritica deslocada por um conjunto de falhas normais; C) vista da Cachoeira do Tarumã exibindo no topo um nivel do "Arenito Manaus"; D) exposição da Formação Alter do Chão em voçoroca; E) exposição de folhelhos fossiliferos da Formação Manacapuru; F) contato entre as formações Nhamundá e Pitinga/Manacapuru; G) corredeiras sobre pacotes de quartzo-arenitos da Formação Nhamundá (Rio Urubuí); H) registros da Formação Alter do Chão exibindo horizontes caolinizados e encaixados em graben desenvolvido na Formação Nhamundá. 
tais como planos de cavalgamento, foliações convolutas, diques de injeção e dobras desarmônicas, além de blocos de arenitos dispersos com tamanhos centimétricos a métricos (Soares 1998, Soares et al. 2005).

Ao longo desta seção geológica a Formação Nhamundá é a unidade dominante, a qual está constituída por quartzo-arenitos finos a grossos com estratificações cruzada e plano-paralela, intercalados com folhelhos, siltitos e diamictitos, contendo abundante registros fósseis, com destaque para icnofósseis do tipo Skolithos sp. e Arthrophycus alleghaniensis (Nogueira et al.1999). Essa unidade é considerada como de ambiente litorâneo e plataformal sob influência glacial durante o Neordoviciano ao Eoenlochkoviano (Caputo \& Crowell 1985, Grahn 1991 e 1992, Grahn \& Paris 1992, Cunha et al. 1994, Nogueira et al., 1997a e 1997b).

$\mathrm{Na}$ saída na cidade de Presidente Figueiredo, observa-se outro local de didática exposição do contato entre as formações Nhamundá e Pitinga/Manacapuru lateritizadas, o qual pode ser acompanhado pela rodovia BR-174 até próximo do quilômetro 116. A Formação Pitinga/Manacapuru mostra-se constituída por folhelhos e siltitos com finas intercalações de arenitos finos e leitos de silexito, contendo laminação ondulada, por vezes bioturbados e relacionada à deposição em ambiente marinho plataformal durante o Neolandoveriano-Eoludloviano (Caputo et al. 1972, Grahn 1991 e 1992, Grahn \& Paris 1992, Cunha et al. 1994, Nogueira et al., 1997a)

Ao longo dessa seção geológica os efeitos da neotectônica estão registrados através da geração de diferentes estilos de falhas e fraturas, responsáveis pelo desenvolvimento de corredeiras (Fig. 3G), cachoeiras, grutas e cavernas, feições estas que atraem intensa atividade turístico-ecológica para o Município de Presidente Figueiredo (Nogueira \& Sarges 2001). A neotectônica também é responsável pela geração de estruturas de abatimento do tipo grabens, observados nos quilômetros 103 e 110, os quais guardam registros da sedimentação Alter do Chão sobre a Formação Nhamundá (Fig. 3H), cujos contatos laterais estão encobertos por latossolos e floresta, porém no contato basal é marcado por conglomerados polimiticos (Nogueira et al. 1997b).

Seção Geológica D Esta seção contempla o limite da borda norte da Bacia do Amazonas com o embasamento granítico-vulcânico paleoproterozóico (Fig. 2). O contato entre as rochas sedimentares paleozóicas da Formação Nhamundá e neoproterozóica da Formação Prosperança é marcado por uma discordância erosiva que está encoberta por um extenso platô laterítico bauxítico. Os horizontes mais superiores desse platô laterítico estão expostos entre os quilômetros 127 e 128 da rodovia BR-174 (Fig. 4A), com destaque para crosta de aspecto colunar com 2 a $3 \mathrm{~m}$ de espessura, constituída por óxi-hidróxidos de ferro e alumínio (Horbe et al. 2001, Peixoto 2006, Peixoto \& Horbe 2008).

A Formação Prosperança está distribuída no limite da borda norte da Bacia do Amazonas sob a forma de uma faixa estreita e descontínua (Fig. 1). Na altura do quilômetro 130 da rodovia BR-174, é possível observar, em corte de estrada, registros da Formação Prosperança depositados sobre as rochas embasamento granítico-vulcânico, representado pelo Grupo Iricoumé e Suíte Intrusiva Mapuera (Figs. 4B e 4C). Esse contato discordante erosivo se mostra bastante lateritizado, porém ainda é possível observar o discreto contorno de falhas normais em arranjo lístrico com direção NW-SE e mergulho para SW, testemunho da tectônica distensiva responsável pela geração de áreas abatidas favoráveis à sedimentação durante o Neoproterozóico (Wanderley Filho 1991). A Formação Prosperança mostra-se constituída por níveis conglomeráticos, pacotes de arenitos feldspáticos finos a grossos e siltitos de cor vermelho amarronzado, com mergulhos de até $9^{\circ}$ para Sul, contendo laminação plano-paralela, estratificação cruzada de baixo ângulo, marcas de ondas e paleocanais (Caputo et al. 1972, Cunha et al. 1994, Nogueira \& Soares 1996, Nogueira 1999).

As rochas do Grupo Iricoumé são representadas por depósitos de fluxo piroclástico intercalados com derrames vulcânicos ácidos a intermediários (Araújo Neto \& Moreira 1976, Valério et al. 2005, Valério 2006). Os depósitos piroclásticas são representados principalmente por ignimbritos, co-ignimbritos e ignimbritos eutaxiticos, com registros subordinadas de brechas autoclástias ou co-ignimbriticas, tufos, lapilli tufos e bomba-lapilli tufos (Marques et al. 2007, Freitas et al. 2007, Souza et al. 2007). Em geral, essas rochas exibem cor cinza rosada, marcante acamamento plano-paralelo e granulação fina a média (Fig. 4D), constituídos por cristaloclastos, litoclastos, púmices e shards soldados por uma matriz microcristalina e vitroclástica, achatados e contendo estruturas amigdalóidais associadas ao alívio de gases. Os derrames vulcânicos ácidos são compostos por riolitos a riodacitos de cor cinza rosada a vermelho claro, textura porfirítica fina a média, ressaltada por fenocristais de feldspatos e quartzo imersos em matriz fina a média de composição quartzo-felspática, contendo amígdalas e estruturas de fluxo magmático (Fig. 4E). Já os derrames intermediários são pouco comuns e estão representados por andesitos a traqui-andesitos de cor preto a cinza esverdeado, arranjo textural porfirítico fino a médio ressaltado por fenocristais de plagioclásio imersos em matriz fina a afanítica (Fig. 4F), contendo também amígdalas e textura de fluxo magmático (Souza et al. 2007). Segundo Valério et al. (2005) e Valério (2006), os derrames ácidos a intermediários Iricoumé, nesse trecho da rodovia BR-174, apresentam composição meta a peraluminosa, subalcalina de alto-K e a idade $\mathrm{Pb}-\mathrm{Pb}$ em zircão do litotipo riolito porfirítico epizonal é de $1.883 \pm 4 \mathrm{Ma}$.

As rochas do Grupo Iricoumé são intrudidas por maciços graníticos Mapuera, os quais hospedam xenólitos de rochas vulcânicas (Fig. 4G), expostos no Ramal do Castanhal e ao longo da rodovia BR-174, com destaque para os batólitos São Gabriel e Abonari. Em geral, esses granitos exibem cor vermelho a rosa claro, arranjo textural inequigranular a porfirítico médio a grosso, por vezes granofírico e até milonítico, com assembléia mineral à base de microclínio pertítico, quartzo, oligo- 

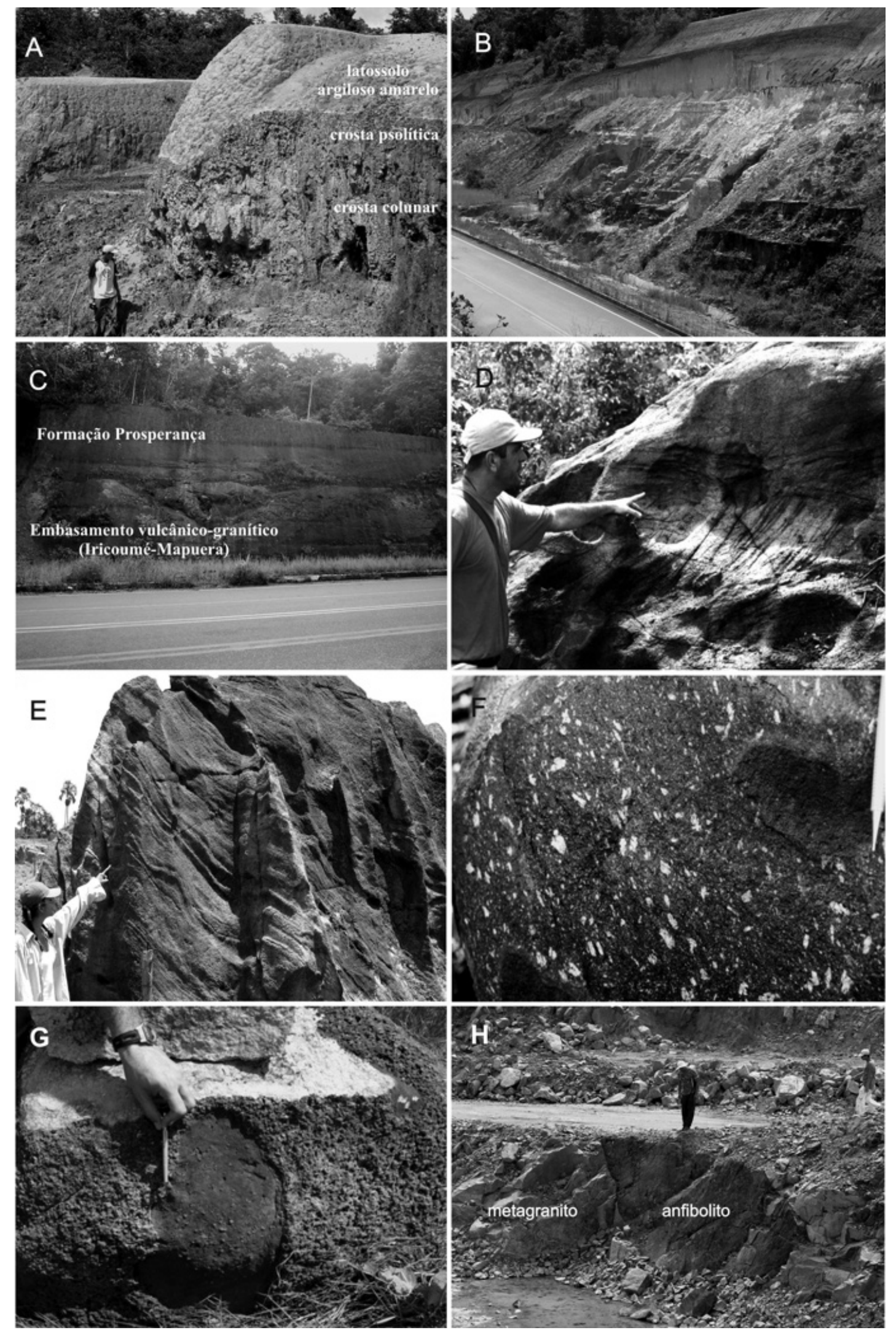

Figura 4 - A) crosta Fe-Al de aspecto colunar na base e pisolitico no topo, recoberta por latossolo argiloso; B) exposição de pacotes de arenitos e siltitos da Formação Prosperança; $C$ ) contato entre a Formação Prosperança e o embasamento granítico-vulcânico paleoproterozóico; D) aspecto textural de fluxo piroclástico ignimbriticos acamadados do Grupo Iricoumé; E) estruturas de fluxo magmático em riolitos do Grupo Iricoumé; F) arranjo textural porfirítico de andesitos do Grupo Iricoumé; G) xenólito de rochas piroclásticas do Grupo Iricoumé em biotita granito São Gabriel da Suite Intrusiva Mapuera; H) frente de lavra para brita sobre rochas do Complexo Jauaperi. 
clásio e biotita, definindo composição sienogranítica. De acordo com Valério (2006) e Valério et al (2006a), os granitos Mapuera são fracamente peraluminosos, subalcalinos de alto- $\mathrm{K}$ e a idade $\mathrm{Pb}-\mathrm{Pb}$ em zircão do batólito São Gabriel é de $1.889 \pm 2$ Ma.

As rochas vulcânicas e graníticas dos magmatismos Iricoumé e Mapuera mostram-se, ocasionalmente, atravessadas por diques de diabásio e olivina grabro (Araújo Neto \& Moreira 1976, Veiga Jr. et al. 1979, Valério 2006). Os registros desse magmatismo básico na região têm sido agrupados em dois eventos: a) o primeiro do Proterozóico, com idade K-Ar na ordem de 1.0 a 1.1 Ga (Araújo Neto \& Moreira 1976), o qual foi posteriormente agrupado na Formação Seringa (Veiga Jr. et al. 1979) e, provavelmente, estar relacionado à fase extensional que culminou com a sedimentação da Formação Prosperança; e b) o segundo é considerado do Mesozóico (Santos et al. 1974, Veiga Jr. et al. 1979) e correlacionado aos diques e soleiras de diabásio de idade neotriássica da Bacia do Solimões (Alves et al. 2002). Entretanto, recentes trabalhos de campo identificaram no extremo oeste da área uma intrusão gabróica (Fig. 1), cujos aspectos petrográficos, geoquímicos e geocronológicos ainda estão sendo adquiridos e poderão trazer novas considerações genéticas sobre esse magmatismo básico.

Seção Geológica E Esta seção retrata as relações de contato entre o Complexo Jauaperi, Grupo Iricoumé e as suítes intrusivas Mapuera e Água Branca, além do registro de rochas da Formação Prosperança preenchendo estrutura de abatimento tipo graben (Fig. 2).

Entre os quilômetros 150 e 153 da rodovia BR174, excelentes exposições de rochas metamórficas, aqui interpretadas como representantes do Complexo Jauaperi, podem ser observadas nas frentes de lavra das pedreiras que produzem brita para o setor de construção civil na região (Fig. 4H). Nesses locais ocorrem metavulcânicas ácidas, metagranitos, diques de anfibolitos e corpos pegmatíticos, além de veios e vênulas de quartzo, brechas e zonas de cisalhamento rúptil-dúctil com registros atividade hidrotermal de natureza propilítica. Em geral, essas rochas apresentam feições de recristalização granoblástica heterogranular fina a média, variando localmente para tipos miloníticos porfiroblásticos, interpretados como produtos de deformação e metamorfismo dinâmico (Souza et al. 2006). Entretanto, é possível também que essas feições de recristalização sejam produtos de metamorfismo de contato, gerado pelo magmatismo batolítico São Gabriel, cujas relações de contato com as encaixantes nessa porção da rodovia BR-174 ainda não estão bem esclarecidas.

Entre os quilômetros 161 e 163 da rodovia BR174, são registrados também excelentes exposições das rochas da Formação Prosperança depositadas em graben orientado na direção WNW-ESE e desenvolvido em rochas vulcânicas Iricoumé, cujos limites laterais são marcados por conjuntos de falhas normais sindeposicionais e zonas de cisalhamento, testemunhos da ação de uma tectônica transcorrente na arquitetura do sitio deposicional (Fig. 5A). Segundo Nogueira \& Soares (1996) e Nogueira (1999), essas exposições hospedam cinco associações faciológicas (distributário fluvial, desembocadura de baía, canal de crevasse, preenchimento de baía e shoreface com tempestitos), marcadas por vários tipos de estratificações cruzadas (acanalada, tabular, planoparalela e swaley), laminações, marcas de ondas, lags conglomeráticos, acamamento wavy-linsen e paleo-canais (Figs. 5B e 5C).

Os registros da Suíte Intrusiva Água Branca na região são encontrados, principalmente, ao longo dos ramais Canoas e Rumo Certo. Em geral, são representados por stocks de cor cinza claro, inequigranulares a porfiríticos médios (Fig. 5D), por vezes exibindo feições de fluxo magmático e miloníticas, são constituídos por fenocristais de microclínio pertítico e oligoclásio, imersos em matriz a base de quartzo, microclínio, oligoclásio, biotita e/ou hornblenda. Valério (2006) individualizou tipos petrográficos que variam de monzogranitos a dioritos, de composição meta a peraluminosa, subalcalinos de médio a alto- $\mathrm{K}$ e cujas idades $\mathrm{Pb}-\mathrm{Pb}$ em zircão variam de 1898 a 1890 Ma.

Seção Geológica $\mathbf{F}$ A última etapa desse roteiro-guia contempla a volumosa associação vulcano-plutônica paleoproterozóica Iricoumé-Mapuera (Fig. 2), representante do magmatismo Uatumã que afetou o sul do Escudo das Guianas (Santos et al. 2000, Tassinari \& Macambira 2004). Nesta seção há o amplo predomínio de rochas graníticas Mapuera que interpenetram registros de vulcânicas ácidas a intermediárias Iricoumé, com destaque para batólito granítico Abonari, cuja idade U-Pb em zircão é de $1.871 \pm 5 \mathrm{Ma}$. (Santos et al. 2001, Reis et al. 2006). Excelentes exposições desse maciço granítico são encontradas em pedreiras abandonadas nos quilômetros 199 e 202 da rodovia BR-174 (Fig. 5E). A rocha exibe cor vermelho escuro com matizes azulados, textura isotrópica inequigranular média a grossa e constituída por K-feldspato pertítico, quartzo, oligoclásio, hornblenda e biotita, definindo composição sienogranítica, contém freqüentes enclaves máficos (Fig. 5F) e fraturas na direção NE-SW. Segundo Araújo Neto \& Moreira (1976), o batólito granítico Abonari exibe composição química meta a peraluminosa, com tendência alcalina de alto-K.

CONSIDERAÇÕES FINAIS A região entre os municípios de Manaus e Presidente Figueiredo hospeda registros importantes para a compreensão dos eventos magmáticos ocorridos durante o Paleoproterozóico no sul do Escudo das Guianas e dos depósitos sedimentares formados durante o Paleozóico-Cenozóico na Bacia do Amazonas, bem como dos processos pedogenéticos e tectônicos cenozóicos superimpostos. Entretanto, algumas questões envolvendo, principalmente, o embasamento e a natureza do magmatismo Paleoproterozóico ainda carecem de investigações petrológicas e geocronológicas.

Quanto ao embasamento, a principal questão reside nos dados a respeito da natureza e idade dos eventos tectono-metamórficos impressos nas rochas do 

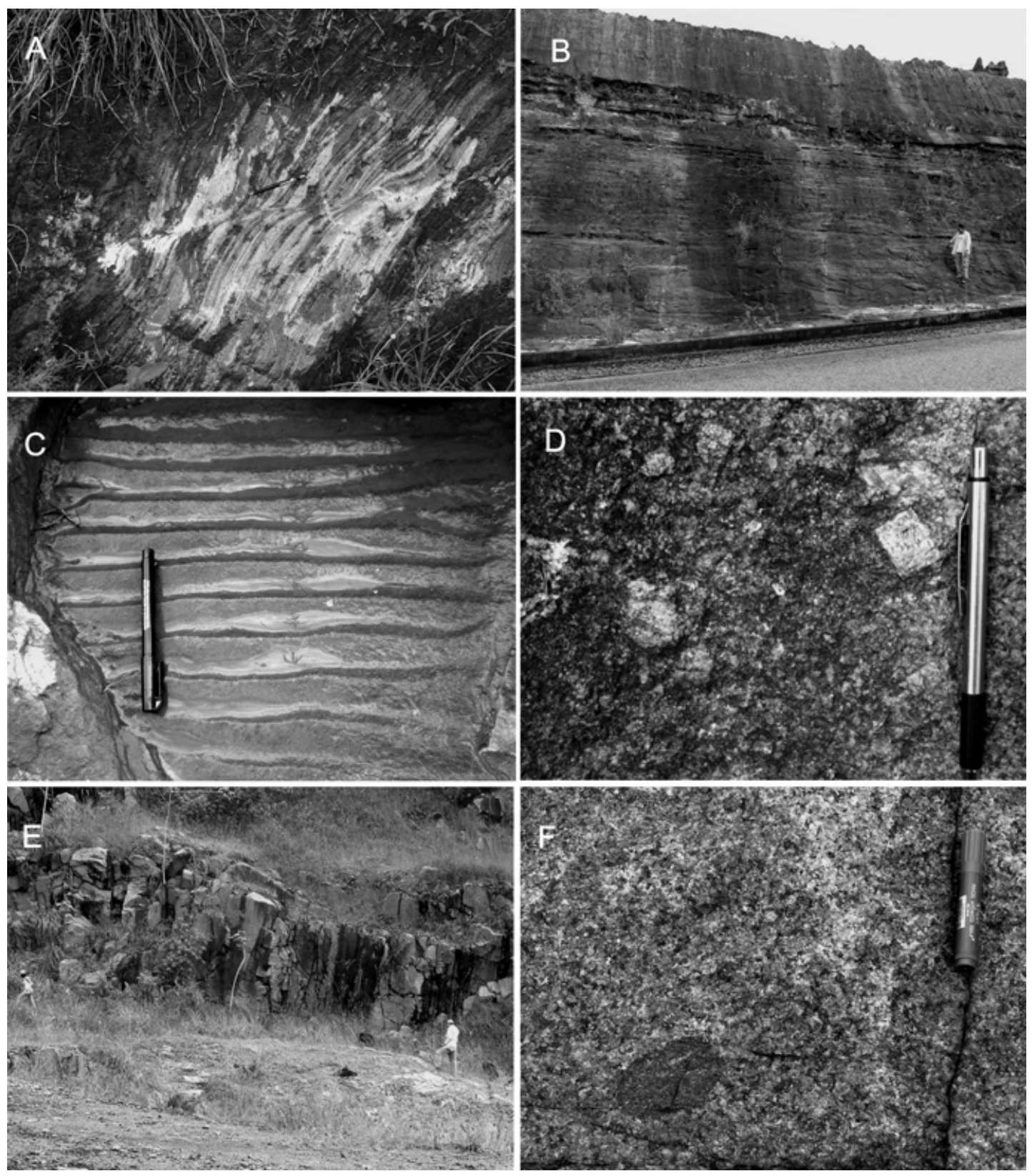

Figura 5 - A) zona de cisalhamento em regime dúctil desenvolvida em rochas piroclásticas lateritizadas do Grupo Iricoumé marcando o limite lateral $S W$ da estrutura em graben que hospeda rochas da Formação Prosperança; B) exposição em corte de estrada da Formação Prosperança encaixada em graben desenvolvido sobre rochas do Grupo Iricoumé; C) marcas de onda na Formação Prosperança; D) aspecto textural porfirítico médio a grosso dos granitos da Suíte Intrusiva Água Branca; E) frente de pedreira para brita no batólito granítico Abonari; F) aspecto textural do granito Abonari contendo enclaves máficos.

Complexo Jauaperi, os quais ainda são insatisfatórios. Isto porque as informações geocronológicas disponíveis para gnaisses e metagranitos do Complexo Jauaperi apresentam idades U-Pb em zircão entre $1867 \pm 15$ e $1880 \pm 3 \mathrm{Ma}$ (Reis et al. 2006), as quais são muito próximas das idades obtidas para o magmatismo pós-colisional anorogênico Iricoumé-Mapuera (1,89-1,88 Ga).

Quanto ao magmatismo Paleoproterozóico, têm sido identificados sucessivos eventos com características geoquímicas, geocronológicas e de ambiência tec- tônica distintas. Valério (2006) e Valério et al. (2006b) identificam dois eventos com idades $\mathrm{Pb}-\mathrm{Pb}$ em zircão entre 1,89 e 1,88 Ga: a) magmatismo Água Branca, representado por granitos do tipo I alojados em ambiente sin-colisional (crosta oceânica-crosta continental); e b) magmatismo Iricoumé-Mapuera, considerado de ambiente pós-colisional a intraplaca, alojado durante uma fase transtensiva. Ferron (2006) considera para o distrito minerador do Pitinga, localizado a cerca de $50 \mathrm{~km}$ ao norte da região aqui apresentada (Fig. 1), a atuação de 
três eventos magmáticos progressivos entre 1,96 e 1,81 Ga: a) magmatismo cálcio-alcalino Água Branca (1,96$1,94 \mathrm{Ga}$ ), alojado em ambiente sin-colisional com forte interação entre magmas mantélico e crustal; b) vulcanoplutonismo alcalino Iricoumé-Mapuera $(1,89-1,88 \mathrm{Ga})$, alojado em ambiente pós-colosional a anorogênico, e c) magmatismo alcalino a peralcalino da Suíte Intrusiva Madeira (1,82-1,81 Ga), responsável pelos plutons graníticos anorogênicos com mineralização polimetálica. Já na região entre o sudeste de Roraima e o nordeste do Amazonas, Almeida (2006) e Almeida \& Macambira (2007) identificaram três eventos magmáticos progressivos ocorridos entre 1,90 e 1,87 Ga: a) magmatismo cálcio-alcalino do tipo I, de idade entre 1,90 e 1,89 Ga e representado pela suíte Intrusiva Água Branca; e b) dois eventos graníticos intrusivos do tipo A, representados pelos granitos e Mapuera-Abonari $(\sim 1,87 \mathrm{Ga})$ e Moderna $(\sim 1,81 \mathrm{Ga})$.

Em relação aos depósitos sedimentares précambrianos e fanerozóicos, apesar das informações paleoambientais pontuais, esses fornecem um escopo bem razoável da história sedimentar na região. Os depósitos flúvio-litorâneos da Formação Prosperança estão mais ligados a um evento deposicional anterior à formação da Bacia do Amazonas, refletindo um estágio rifte entre o final do Neoproterozóico e o início do Paleozóico, associado a eventos transtensivos posteriores ao ciclo Brasiliano (Cunha et al. 1994, Silva et al. 2003). Por outro lado, os depósitos da Bacia do Amazonas refletem um estágio de sinéclise com deposições dominantemente costeiras a marinhas, parcialmente influenciadas por glaciações no Devoniano (Cunha et al. 1994). Pesquisas geológicas e paleontológicas têm demonstrado que a evolução da Bacia do Amazonas envolveu inversão do fluxo da drenagem, a qual migrava primeiramente para oeste e noroeste, em direção ao Pacífico, e há cerca de 15 milhões de anos atrás, motivada pelo soerguimento dos Andes, mudou para leste em direção ao Atlântico (Nogueira 2008). Entretanto, apesar dos intervalos de idades das rochas paleozóicas estarem praticamente definidos, ainda restam dúvidas quanto ao intervalo de deposição das formações Prosperança e Alter do Chão, devido à escassez de material apropriado para a datação, tais como palinomorfos ou rochas vulcânicas intercaladas.

Quanto aos registros geológicos do Cenozóico, a região se destaca pela presença de perfis lateríticos autóctones caulínicos e bauxiticos desenvolvidos sobre diferentes tipos de rochas a partir do Paleógeno (Costa \& Moraes 1998, Horbe et al. 2001, Peixoto 2006, Peixoto \& Horbe 2008), cujos aspectos de viabilidade econômica vêem sendo retomados por empresas do setor mineral. Outro importante registro geológico é a atividade da neotectônica, desenvolvida do Mioceno ao Recente e responsável por alterações nas morfologias do relevo e fluvial, com destaque para os diferentes estilos de falhas que abateram ou soergueram blocos de rochas gerando desníveis topográficos, além feições anômalas dos tipos rios retilíneos, corredeiras e cachoeiras, migração de canais fluviais e outras (Iriondo 1982, Franzinelli \& Piuci 1988, Franzinelli \& Igreja 1990, Costa et al. 1996 e 2001).

Agradecimentos Aos projetos de pesquisas Casadinho UFAM-UFPA (MCT/CNPq Proc. № 620034/20068) e CT-Amazônia (MCT/CNPq Proc. № 575520/20086) pelo apoio financeiro aos trabalhos de campo. Aos professores e estudantes do Departamento de Geociências da Universidade Federal do Amazonas (DEGEOUFAM), em especial aos professores Albertino Carvalho, Adriana Horbe, Cláudio Milliotti, Emílio Soares e Lucindo Fernandes Filho, pelas discussões durante os trabalhos de campo. Ao Serviço Geológico do Brasil (CPRM-Manaus) pelo irrestrito apoio às atividades de ensino e pesquisa do DEGEO-UFAM.

\section{Referências}

Albuquerque O.R. 1922. Reconhecimento no Vale do Amazonas. Bol. Serv. Geol. e Mineral. Rio de Janeiro, 3:184.

Almeida M.E. \& Macambira M.J.B. 2003. Aspectos geológicos e litoquímicos dos granitóides cálcio-alcalinos paleoproterozóicos do sudeste de Roraima. In: SBGq, Congr. Brasil. Geoq., 9, Belém, Anais, p.775-778.

Almeida M.E. 2006. Evolução geológica da porção centrosul do Escudo das Guianas com base no estudo geoquímico, geocronológico e isotópico dos granitóides paleoproterozóicos do sudeste de Roraima, Brasil. Tese de Doutoramento, Centro de Geociências, Universidade Federal do Pará, 227p.

Almeida M.E. \& Macambira M.J.B. 2007. Geology and petrography of paleoproterozoic granitoid rocks from Uatumã-Anauá Domain, central region of Guyana Shield, southeastern Roraima, Brazil. Rev. Bras. Geoc., 37(1):237-256.
Alves D.B., Mizusaki A.M.P., Wanderley Filho J.R. 2002. Soleira de diabásio da Bacia do Solimões. In: SBG/NO, Simp. Vulcan. Amb. Assoc., 2, Belém, Boletim de resumos, p.52.

Araújo J.F.V., Montolvão R.M.G., Lima M.I.C., Fernandes P.E.C.A., Cunha F.M.B., Fernandes C.A.C., Basei M.A.S. 1976. Folha SA.21-Santarém (Levantamento de Recursos Naturais). Projeto RADAMBRASIL, MME/ DNPM, Rio de Janeiro, Geologia, 10:9-130.

Araújo Neto H. \& Moreira H.L. 1976. Projeto Estanho de Abonari. MME/DNPM/CPRM. Brasília, vol.1, 232p.

Caputo M.V., Rodriguez R., Vasconcelos D.N.N. 1972. Nomenclatura Estratigráfica da Bacia do Amazonas: histórico e atualização. In: SBG, Congr. Brasil. Geol., 26º Belém, Anais, 3:35-46.

Caputo M.V. 1984. Stratigraphy, tectonics, paleoclimatology, and paleogeography of northern basins of Brazil. $\mathrm{PhD}$ Thesis. Universiy of California, 586p. 
Costa J.B.S., Bemerguy R.L., Hasui Y., Borges M.S., Ferreira Jr. C.R.P., Bezerra P.E.L., Costa M.L., Fernandes J.M.G. 1996. Neotectônica da região Amazônica: aspectos tectônicos, geomorfológicose deposicionais. Geonomos, $\mathbf{I V}(2): 23-44$.

Costa J.B.S., Bemerguy R.L., Hasui Y., Borges M.S. 2001. Tectonics and paleogeography along the Amazon River. Jour. South Amer. Earth Sc., 14:335-347.

Costa M.L. \& Moraes E.L. 1998. Mineralogy, geochemistry and genesis of kaolins from the Amazon region. Mineral. Dep., 33:283-297.

Costi H.T., Santiago A.F., Pinheiro S.S. 1984. Projeto Uatumã-Jatapu. MME/CPRM, Manaus, 133p.

Costi H.T., Dall'Agnol R., Moura C.A.V. 2000. Geology and $\mathrm{Pb}-\mathrm{Pb}$ geochronology of Paleoproterozoic volcanic and granitic rocks of the Pitinga Province, northern Brazil. Intern. Geol. Rev., 42:832-849.

CPRM. 2002. Geologia e recurso minerais da Amazônia brasileira, região cratônica. SIG-Brasil, Mapa escala 1:750.000, CD-ROM.

Cunha P.R.C., Gonzaga F.G., Coutinho L.F.C., Feijó F.J. 1994. Bacia do Amazonas. Bol. Geoc. Petrobr., 8(1):4755.

Daemon R.F. 1975. Contribuição à datação da Formação Alter do Chão, Bacia do Amazonas. Rev. Bras. Geoc., 17:382-403.

Dino R., Silva O.B., Abrahão D. 1999. Caracterização palinológica e estratigráfica de estratos cretáceos da Formação Alter do Chão, Bacia do Amazonas. In: SBG-SE, Simp. Cret. Bras., 5, Rio Claro, Atas, p.557-565.

Eiras J.F., Becker C.R., Souza E.M., Gonzaga J.E.F., Silva L.M., Daniel L.M.F., Matsuda N.S., Feijó F.J. 1994. Bacia do Solimões. Bol. Geoc. Petrobr., 8(1):17-45.

Faria M.S.G., Luzardo R., Oliveira M.J.R. 2000. Suite Intrusiva Água Branca. Programa de Levantamentos Geológicos Básicos do Brasil, Folha Caracaraí (RR), 1:500.000. Manaus, CPRM-AM, 3:57-82.

Faria M.S.G. \& Luzardo R. 2000. Complexo Metamórfico Anauá. Programa de Levantamentos Geológicos Básicos do Brasil, Folha Caracaraí (RR), 1:500.000. Manaus, CPRM-AM, 3:57-82.

Fernandes Filho L.A. 1966. Geologia, mineralogia, geoquímica dos lateritos de Manaus-Amazonas. Dissertação de Mestrado, Centro de Geociências, Universidade Federal do Pará, 96p.

Ferron J.M.T.M. 2006. Geologia regional, geoquímica e geocronologia $\mathrm{Pb}-\mathrm{Pb}$ de rochas graniticas e vulcânicas paleoproterozóicas da Província Pitinga, cráton Amazônico. Tese de Doutoramento, Instituto de Geociências, Universidade Federal do Rio Grande do Sul, 331p.

Franzinelli E. \& Piuci J. 1988. Evidências de neotectonismo na Bacia Amazônica. In: SBG, Congr. Latino-Amer. Geol., 7, Belém, Anais, p.80-90.

Franzinelli E. \& Igreja H.L.S.1990. Utilização do sensoriamento remoto na investigação na área do baixo Rio Negro e grande Manaus. In: SBG, Simp. Brasil. Sensor. Remoto, 6, Manaus, Atas, 3:641-648.

Freitas M.E., Chagas A.N.B., Araújo F.M., Mejia N.I.M. 2007. Interpretação das texturas das rochas vulcânicas do Grupo iricoumé na região de presidente Figueiredo -
AM. In: SBG-NO, Simp. Geol. Amaz., 10, Porto Velho, p.121-124, CD-Rom.

Fuck R.A., Pimentel M.M., Machado N., Daoud W.K. 1993. Idade U-Pb do granite Madeira, Pitinga (AM). In: SBG, Congr. Bras. Geoq., 4, Brasília, Anais, p.246-248.

Grahn C.Y. 1991. Ordovician Chitinozoa and biostratigraphy of Brazil. Geobios, 25(6):703-723.

Grahn C.Y. 1992. Revision of silurian and Devonian Strata of Brazil. Palinology, 16:35-61

Grahn C.Y. \& Paris F. 1992. Age and correlation of the Trombetas Group, Amazonas Basin, Brazil. Rev. Micropaléont., 35:197-209.

Horbe A.M.C., Nogueira A.C.R., Soares E.A.A., Souza V.S. 1999. A lateritizaçã na evolução morfológica da região de Presidente Figueiredo - Estado do Amazonas. In: SBG-NO, Simp. Geol. Amaz., 6º Manaus, Atas, p.399402.

Horbe A.M.C., Nogueira A.C.R., Horbe M.A., Costa M.L., Suguio K. 2001. A lateritização da gênese das superfícies de aplainamento da região de Presidente Figueiredo Balbina, nordeste do Amazonas. In: Reis N.J. \& Monteiro M.A.S (coord.). Contribuições à Geologia da Amazônia. Manaus, SBG-NO, vol. 2, p.145-176.

Horbe A.M.C., Horbe M.A., Suguio K. 2004. Tropical spodosols in northeastern Amazonas State, Brazil. Geoder$m a$, 119:55-68.

Iriondo M. 1982. Geomorfologia da planície Amazônica. In: SBG, Simp. Quatern. Brasil, 4, Atas, p.323-348.

João X.S.J., Santos C.A., Faraco M.T.L. 1984. Projeto Trombetas-Mapuera. Belém, DNPM/ CPRM, vol.1, 234p.

Lenharo S.L.R. 1998. Evolução magmática e modelo metalogenético dos granitos mineralizados da região de Pitinga, Amazonas, Brasil. Tese de Doutoramento, Escola Politécnica, Universidade de São Paulo, 290p.

Macambira M.J.B., Teixeira J.T., Daoud W.E.K., Costi H.T. 1987. Geochemistry, mineralizations and age of tinbearing granites from Pitinga, northwestern Brazil. Rev. Bras. Geoc., 17(4):562-570

Marques S.N.S., Nascimento R.S.C., Souza V.S., Dantas E.L. 2007. Características geoquímicas das rochas vulcânicas do Grupo Iricoumé, em perfis estratigráficos, na região de Presidente Figueiredo - AM. In: SBG-NO, Simp. Geol. Amaz., 10, Porto Velho, Atas, p.221-224, CD-Rom.

Monteiro E.A., Nava D.B., Correia M.C. 1998. Programa de Integração Mineral em Municípios da Amazônia - PRIMAZ. Manaus, MME/CPRM, CD-ROM.

Nogueira A.C.R. \& Soares E.A.A. 1996. Fácies sedimentares da Formação Prosperança, proterozóico Superior da Bacia do Amazonas, ao norte da cidade de Manaus - AM. In: SBG-NO, Simp. Geol. Amaz., 5, Belém, Atas, p.214216, CD-Rom.

Nogueira A.R., Soares E.A.A., Souza V., Trunckenbrodt W., Caputo M.V. 1997a. Estruturas glaciotectônicas na Formação Nhamundá, Siluriano da Bacia do Amazonas. In: SBG, Simp. de Est. Tect., 5, Pirinópolis, Atas, p.153155.

Nogueira A.R., Souza V., Soares E.A.A. 1997b. Contribuição à tectônica cenozóica da região de Presidente Figueiredo, norte de Manaus - AM. In: SBG, Simp. Est. Tect., 5, Pirinópolis, Atas, p. 123-125. 
Nogueira A.C.R., Truckenbrodt W., Soares E.A.A. 1999. O icnogênero Arthrophyvus de depósitos sublitorâneos da Formação Nhamundá (Siluriano inferior) da bacia do Amazonas, região de Presidente Figueiredo. Rev. Bras. Geoc., 29(2):135-140.

Nogueira A.C.R. 1999. Depósitos costeiros neoproterozóicos da Formação Prosperança, Município de presidente Figueiredo, Estado do Amazonas. In: SBG-NO, Simp. Geol. Amaz., 6, Manaus, Atas, p.412-415.

Nogueira A.C.R \& Sarges R.R. 2001. Characterization and gênesis of waterfalls of the Presidente Figueiredo region, northeast state of Amazonas, Brazil. An. Acad. Bras. Ciênc., 73(2):287-301.

Nogueira A.C.R., Silva Júnior J.B.C., Horbe A.M.C., Soares J.L., Monteiro A.D. 2003. A Gênese dos níveis silicificados da Formação Alter do Chão, Cretáceo Superios da Bacia do Amazonas. In: SBG/NO, Simp. Geol. Amaz., 8, Manaus, CD-Rom.

Nogueira A.C.R. 2008. Guinada para o Atlântico. In: Furtado R. (coord.) Scientific American Brasil. Coleção Amazônia Origens, 1:22-27.

Oliveira M.J.R., Almeida M.E., Luzardo R., Faria M.S.G. 1996. Litogeoquímica da Suíte Intrusiva água Branca SE de Roraima. In: SBG, Congr. Brasil. Geol., Anais, 39, 2:213-216.

Peixoto S.F. 2006. Mineralogia e geoquímica de perfis lateriticos no nordeste do Estado do Amazonas. Dissertação de Mestrado, Departamento de Geociências, Universidade Federal do Amazonas, Manaus, 122p.

Peixoto S.F. \& Horbe A.M.C. 2008. Bauxitas do nordeste do Amazonas. Rev. Bras. Geoc., 38(2):406-422.

Ramos M.I.F., Silva M.B., Bosetti E., Soares E.A.A. 2001. Registro inédito de macrofósseis paleozóicos na Formação Manacapuru, Região de Presidente Figueiredo, Bacia do Amazonas. In: Congr. Brasil. de Paleontol., 16, Rio Branco, Anais, p. 183.

Reis N.J., Almeida M.E., Riker S.L., Ferreira A.L. 2006. Geologia e recursos minerais do Estado do Amazonas. MME/CPRM/CIAMA, Programa de Geologia do Brasil (mapas geológicos estaduais, escala 1:1.000.000), Manaus, $125 \mathrm{p}$.

Santos J.O.S., Moreira A.S., Pessoa M.R., Oliveira J.R., Malouf R.F., Veiga Jr. J.P., Nascimento J.O. 1974. Projeto Norte da Amazônia, domínio Baixo Rio Negro. Relatório Final Intergrado, Manaus, DNPM/CPRM, v. 4.

Santos J.O.S., Hartmann L.A., Gaudette H.E., Groves D.I., McNaughton N.J., Fletcher I.R. 2000. A New understand of the provinces of the Amazon Craton based on integration of field mapping and $\mathrm{U}-\mathrm{Pb}$ and $\mathrm{Sm}-\mathrm{Nd}$ geochronology. Gondw. Res., 3(4):453-488.

Santos J.O.S., Groves D.J., Hartmann L.A., Moura M.A., McNaughton N.J. 2001a. Gold deposits of the Tapajós and Alta Floresta Domains, Taajós-Parima orogenic belt, Amazon Craton, Brazil. Mineral. Depos., 36:278-299.

Santos J.O.S., Faria M.S.G., Hartmann L.A., McNaughton N.J., Fletcher I.R. 2001b. Oldest charnochite magmatism in the Amazon Craton: zircon U-Pb SHRIMP geochronology of the Jaburu Charnockite, southern Roraima, Brazil. In: SBG-NO, Simp. Geol. Amaz., 7, Belém, Atas, p. 4. CD- Rom.
Santos J.O.S., Faria M.S.G., Hartmann L.A., McNaughton N.J. 2002. Significant presence of the Tapajós-Parima Orogenic Belt in the Roraima region, Amazon Craton based on SHRIMP U-Pb zircon geochronology. In: SBG, Congr. Brasil. Geol., 41, Araxá, Anais, p. 336.

Santos J.O.S. 2003. Geotectônica dos Escudos das Guianas e Brasil-Central. In: Bizzi LA., Schobbenhaus C., Vidotti R.M., Gonçalves J.H. (eds.) Geologia, Tectônica e Recusrsos Minerais do Brasil (texto, mapas \& SIG). Brasília, Serviço Geológico do Brasil - CPRM/MME, p.169-226.

Santos J.O.S., Hartmann L.A., Faria M.S.G., Riker S.R., Souza M.M., Almeida M.E., McNaughton N.J. 2006. A compartimentação do Cráton Amazonas em províncias: avanços ocorridos no período 2000-2006. In: SBG-NO, Simp. Geol. Amaz., 9, Belém, CD-Rom.

Silva A.J.P., Lopes R.C., Vasconcelos A.M., Bahia R.B.C. 2003. Bacias sedimentares paleozóicas e meso-cenozóicas interiores. In: Bizzi L.A., Schobbenhaus C., Vidotti R.M., Gonçalves J.H. (eds.) Geologia, Tectônica e Recusrsos Minerais do Brasil (texto, mapas \& SIG). Brasília, Serviço Geológico do Brasil - CPRM/MME, p.55-85.

Silva C.L. 2005. Análise da tectônica cenozóica da região de Manaus e adjacências. Tese de Doutoramento. Instituto de Geociências e Ciências Exatas, UNESP-Rio Claro (SP), 279p.

Soares E.A.A. 1998. Fácies litorâneas e feições glaciais da Formação Nhamundá (Siluriano Inferior) na região de Presidente Figueiredo - AM, Bacia do Amazonas. Dissertação de Mestrado, Centro de Geociências, Universidade Federal do Pará, 98p.

Soares E.A.A., Truckenbrodt W., Nogueira A.C.R. 2005. Fácies litorâneas e subglaciais da Formação Nhamundá (Siluriano inferior), região de Presidente Figueiredo, Bacia do Amazonas. Bol. Mus. Para. Emílio Goeldi., 2:105-132.

Soares J.L. \& Nogueira A.C.R. 2006. Traços-fósseis silurodevonianos do Grupo Trombetas da Bacia do Amazonas na Região de Presidente Figueiredo-AM. In: SBG/NO, Simp. Geol. Amaz., 9, Belém, CD-Rom.

Souza M.M. 1974. Perfil geológico BR-174 (Manaus-Boa Vista): No trecho Manaus-Serra do Abonari. In: SBG, Congr. Brasil. Geol., 28, Porto Alegre, Anais, 29-33.

Souza A.G.H., Milliotti C.A., Luzrdo R. 2006. Aspectos petrográficos das rochas ácidas e diques básicos na pedreira do Getúlio, região de Presidente Figueiredo (AM). In: SBG-NO, Simp. Geol. Amaz., 9, Belém, CD-Rom.

Souza V.S., Marques S.N.S., Nascimento R.S.C., Valério C.S. 2007. Texturas e estruturas em rochas piroclásticas e vulcânicas paleoproterozóicas do Grupo iricoumé, sudeste do Município de Presidente Figueiredo. In: SBGNO, Simp. Geol. Amaz., 10, Proto Velho, Atas, p.61-64, CD-Rom.

Tassinari C.C.G. \& Macambira M.J.B. 1999. Geochronological provinces of the Amazonian Craton. Episodes, 22(3):174-182.

Tassinari C.C.G. \& Macambira M.J.B. 2004. A evolução tectônica do Cráton Amazônico. In: Mantesso-Neto V., Bartorelli A., Dal Ré Carneiro C., Brito-Neves B.B. (eds.) 
Geologia do Continente Sul-Americano: Evolução da obra de Fernando Flávio Marques de Almeida. São Paulo, Ed. Beca, p.471-485.

Tassinari C.C.G., Bettencourt J.S., Geraldes M.C., Macambira M.J.B., Lafon J.M. 2000. The Amazonian Craton. In: Cordni U.G., Milani E.J., Thomaz Filho A., Campos D.A. (eds.) Tectonic Evolution of South America. Rio de Janeiro, $31^{\text {st }}$ Inter. Geol. Congr, FINEP/CT Petro, 41$95 \mathrm{p}$.

Travassos W.A.S. \& Barbosa Filho C.M. 1990. Tectonismo Terciário na área do Rio Tapajós, Bacia do Amazonas, Bol. Geoc. Petrobr., 4(3):299-314.

Valério C.S., Souza V.S., Macambira M.J.B., Milliotti C.A., Carvalho A.S. 2005. Geoquímica e idade $\mathrm{Pb}-\mathrm{Pb}$ de zircão do Grupo Iricoumé na região da borda norte da bacia do Amazonas, município de Presidente Figueiredo (AM). In: SBG, Simp. Vulcan. e Amb. Assoc., 3, Cabo Frio, Atas, p. 47-52.

Valério C.S. 2006. Magmatismo Paleoproterozóico do estremo sul do Escudo das Guianas, município de Presidente Figueiredo (AM): geologia, geoquímica e geocronologia $\mathrm{Pb}$-Pb em zircão. Dissertação de Mestrado, Departamento de Geociências, Universidade Federal do Amazonas, $112 \mathrm{p}$.

Valério C.S., Souza V.S., Macambira M.J.B., Galarza M.A. 2006a. Aspectos geoquímicos e idade $\mathrm{Pb}-\mathrm{Pb}$ da borda sudeste do batólito São Gabriel, Município de Presidente Figueiredo (AM), Escudo das Guianas: implicações tectônicas. In: SBG-NO, Simp. Geol. Amaz., 9, Belém, CD-Rom.

Valério C.S., Souza V.S., Macambira M.J.B., Galarza M.A. 2006b. Geoquímica e geocronologia $\mathrm{Pb}-\mathrm{Pb}$ em zircão da Suíte Intrusiva Água Branca, Município de Presidente Figueiredo (AM): evidências de colisão no Paleoproterozóico da Amazônia Ocidental. Rev. Bras. Geoc., 36(3)1-13.

Veiga Jr. J.P., Nunes A.C.B., Souza E.C., Santos J.O.S., Amaral J.E., Pessoa M.R., Souza S.A. 1979. Projeto Sulfetos de Uatumã. Manaus, DNPM/CPRM, Relatório Final, v.6.

Vieira L.C. 2002. Paleossolos de depósitos cretácicos da Formação Alter do Chão, nordeste do Amazonas. Dissertação de Mestrado, Departamento de Geociências, Universidade Federal do Amazonas, 74p.

Wanderley Filho J.R. 1991. Evolução estrutural da Bacia do Amazonas e sua relação com o embasamento. Dissertação de Mestrado, Centro de Geociências, Universidade Federal do Pará, 125p.

Wanderley Filho J.R. 1996. A influência de lineamentos proterozóicos na estruturação da Bacia do Amazonas. In: SBG-NO, Simp. Geol. Amaz., 5, Belém, Atas, p.310312.

Manuscrito ID 11653

Submetido em 02 de julho de 2008 Aceito em 12 de março de 2009 